\title{
Hidden treasures: Padua's anatomy theatre
}

\section{Alison Abbott finds that human dissections during the Renaissance were rather respectable after all.}

When passing through Padua in 1786, Johann Wolfgang von Goethe was surprised to find the Italian university's famed anatomical theatre small and dark. "The audience are squashed on top of each other in a tall pointed funnel," he wrote in his book Italian Journey. "They look down the steep sides to a narrow floor where there is a table on which no daylight falls, so the lecturer has to demonstrate by the lamplight." Every winter between 1595 and 1872 , this curious wooden structure was used by anatomy professors to dissect the corpses of prisoners condemned to the gallows.

Temporary and makeshift anatomy theatres had already been put to use for more than a century as Renaissance artists and scientists — Leonardo da Vinci himself partook — tried to understand for themselves how the body was put together. But that in Padua is Europe's oldest surviving permanent anatomical theatre, and rises through two storeys of the fourteenthcentury Bo Palace, the central building of the University of Padua, some 35 kilometres west of Venice. Around 200 students, along with local dignitaries who were granted the best seats, would squeeze into the theatre's elegantly carved oval tiers, each barely 40 centimetres wide. That the structure could bear such concentrated weight is testament to the local skills in woodworking, honed by the demands of shipbuilding. The Republic of Venice made its immense wealth from marine trading.

Contrary to myth, there is no tunnel below the theatre through which bodies were hidden from Vatican spies. It is true that some popes interpreted a papal bull from 1300 as forbidding dissection, although the charter's intention was to stop the practice of cutting up Crusaders' bodies to send them home in a convenient way. But human dissection was legal in the Republic of Venice, far from Rome. The church insisted only that everything was properly administrated and that corpse remains were given a church blessing afterwards.

However, administration could be slow, and medical students demanding. In 1556 Gabriele Falloppio, who described the Fallopian tubes that now bear his name, lobbied magistrates to provide more corpses in case Padua lost students to competing universities in Bologna or Ferrara. Even when the permanent theatre opened at the end of the sixteenth century, official dissections never kept pace with academic need, so unofficial ones were held for smaller audiences in professors' homes or in pharmacies. These dissections were also legal, but students may have occasionally stolen corpses to meet demand.

Musicians were brought in to the theatre to entertain during breaks. After all, a full dissection could take a good two weeks - also the reason why dissections were only tolerable in the cold months. Out of Christian respect, they stopped at the beginning of Lent, 40 days before Easter, whenever it happened to fall.

Dissections were cutting-edge science in Renaissance Italy, and Padua was a major international centre for all disciplines. Its ancient university drew in students and professors from around Europe. These included Poland's Nicolaus Copernicus, who worked out that Earth goes around the Sun rather than the other way around, and the Englishman William Harvey, who deduced how blood circulates in the body. Galileo acquired his first telescope and pointed it to the heavens in Padua, describing his time there as "the eighteen best years of my life". And then, of course, there was Andreas Vesalius from Brussels. Working with an illustrator who was a pupil of the Italian Renaissance painter Titian, Vesalius produced his masterpiece De Humani Corporis Fabrica (On the Fabric of the Human Body) in 1543. It was as radical as Copernicus's De Revolutionibus (On the Revolutions), published in the same year, and it excited further interest in dissection, encouraging the construction of many permanent anatomical theatres around Europe.

These days the anatomical theatre serves only as a museum piece, open to the public for guided tours. But a small hall next to it is still used as a meeting room for medical faculty. The march of centuries is acknowledged here in the sombre display of skulls of noted professors, exhumed during the phrenology frenzy of the 1800s, and in the twentieth-century frescoes complementing those

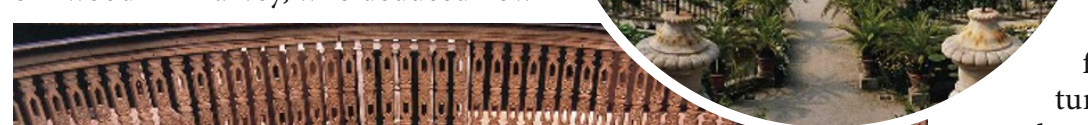
from the sixteenth century. The university has other historical science collections, including its splendid and unique array of eighteenthcentury physics instruments. It also has a charming Renaissance botanical garden, as surprisingly compact as the anatomical theatre - and also the oldest of its kind. Created in 1545, the garden was used to teach students about medicinal plants. Its longest surviving tree is the Goethe palm, planted in 1585. The palm so impressed the great writer-scientist during his Padua sojourn 200 years later that he described it in his 1790 seminal text Metamorphosis of Plants.

Alison Abbott is Nature's Senior European correspondent.

See http://tinyurl.com/56w942 and www.musei.unipd.it/en/index. html for further details.

Padua boasts an anatomy theatre and botanical garden, both Europe's oldest. 